\title{
Bobot dan Persentase Karkas berbagai Jenis Ayam Sentul Jantan Periode Awal
}

\section{Weight and Percentage of Various Types Male Sentul Chicken Carcasses in the Early Period}

\author{
S. N. Hayati*, S. Mulyono, dan Roesdiyanto \\ Department of Poultry Science, Faculty of Animal Science, Jenderal Soedirman University \\ *E-mail: salisa.nimahhayati@gmail.com \\ (Diterima: 5 Agustus 2019; Disetujui: 28 September 2019)
}

\begin{abstract}
ABSTRAK
Tujuan utama penelitian ini adalah mengetahui produksi beberapa jenis ayam sentul jantan periode awal. Materi yang digunakan adalah lima jenis ayam sentul jantan 250 ekor Day Old Chick (DOC) yaitu Ayam Sentul Geni, Sentul Batu, Sentul Kelabu, Sentul Debu, dan Sentul Emas. Metode yang digunakan adalah eksperimen dengan Rancangan Acak Lengkap (RAL). Peubah yang diamati adalah bobot dan persentase meliputi karkas, dada, punggung, sayap, paha, dan giblet (jantung, gizzard, hati). Dari hasil penelitian menunjukkan bahwa berbagai Ayam Sentul berpengaruh nyata terhadap bobot $(\mathrm{P}>0,01)$ dengan rataan $\mathrm{Sa}=25,94 \pm 5,36 \mathrm{~g}$ dan persentase gizzard $(\mathrm{P}>0,05)$ dengan rataan 4,790 $\pm 0,727$, namun terhadap bobot dan persentase karkas, dada, punggung, sayap, paha, jantung dan hati tidak berpengaruh nyata. Kesimpulan penelitian ini menunjukkan bahwa dari berbagai perlakuan berbagai jenis ayam sentul ternyata tidak memberikan perbedaan terhadap produksi karkas ayam sentul jantan di periode awal, kecuali hanya pada produksi dan persentase bobot gizzard.
\end{abstract}

Kata kunci: ayam Sentul, bobot karkas, persentase karkas

\section{ABSTRACT}

This study aims to determine the production of various male sentul chickens in the early period. The experiment used 250 Day Old Chick (DOC) male of sentul chicken with five different variants like Sentul Geni, Sentul Batu, Sentul Kelabu, Sentul Debu, and Sentul Emas. The experiment used Completely Randomized Design (CRD) as our experimental method. Five variables that been observed were the weight and carcass in chest, back, wings, thighs, and giblets (such as heart, gizzard, and liver). The study found that various Sentul Chicken significantly affect only the percentage of gizzard $(P<5 \%)$ and do not significantly affect the percentage of carcass, chest, back, wings, thighs, heart, and liver $(P>0.05)$. This study concludes that various treatment that been applied to different male sentul chicken in early period did not show any significant differences in the production of carcass, except only in the production and percentage of gizzard weight.

Keywords: carcass weight, percentage of carcass, Sentul chicken

\section{PENDAHULUAN}

Menurut Nataamijaya (2010) di Indonesia terdapat setidaknya 32 rumpun ayam lokal yang tersebar di beberapa provinsi. Keberadaan ayam lokal saat ini tersebar hampir di seluruh nusantara. Ayam lokal sebagai plasma nutfah telah mengalami perkembangan dan penambahan populasi dan jenisnya. Ayam lokal merupakan unggas yang dapat dinikmati sebagai ternak konsumsi maupun ternak hias yang dapat dinikmati keindahan bulu dan suara yang dimiliki ayam tersebut.

Salah satu daerah yang memiliki ayam lokal adalah Kabupaten Ciamis. Salah satu diantaranya adalah ayam Sentul. Ayam Sentul kini menjadi perhatian karena memiliki karakteristik dengan lima jenis ayam sentul dan keberadaannya hampir punah. Peternak 
Ayam Sentul sudah melakukan budidaya secara kelompok dengan sistem intensif. Jenis ayam sentul berdasarkan warna bulunya terdiri dari Ayam Sentul Geni, Sentul Batu, Sentul Kelabu, Sentul Debu, dan Sentul Emas (Hartono et al., 2016). Keunggulan ayam sentul diantaranya dapat memproduksi telur yang tinggi sehingga memiliki sifat yang lebih unggul dibandingkan dengan ayam kampung. Selain produksi telur tinggi ayam sentul juga memiliki keunggulan pertumbuhan yang lebih cepat (Solikin et al., 2016). Ukuran produksi dapat diukur dengan perbandingan bobot dan persentase karkas. Pertumbuhan otot, lemak, kulit, dan tulang sebagai komponen karkas memiliki kecepatan tumbuh yang berbeda-beda. Umur dan bobot badan akan berpengaruh terhadap persentase karkas.

Produktifitas ternak daging umumnya dinilai dengan menggunakan persentase karkas. Berat karkas ayam sekitar 66-75 $\%$ dari bobot hidup dan tergantung pada apakah jeroan ikut dimakukkan atau tidak (Oluyemi and Roberts, 1980). Persentase karkas dipengaruhi banyak faktor. Risnajati (2012) berpendapat bahwa presentase karkas selain dipengaruhi oleh faktor genetik seperti bangsa, jenis kelamin, umur, dan kondisi fisik juga dipengaruhi oleh faktor lingkungan.

Dengan demikian, keanekaragaman fenotip pada Ayam Sentul juga berpeluang untuk memberikan produktifitas dan performa yang juga berbeda-beda seperti bobot dan persentase karkas dan bagianbagian karkasnya. Oleh karena itu penelitian ini bermaksud untuk menjawab pertanyaan apakah berbagai jenis Ayam Sentul jantan menghasilkan produksi karkas yang berbeda pada periode awal.

\section{METODE}

Materi yang digunakan adalah lima jenis Ayam Sentul sebanyak 250 ekor Day Old Chick (DOC). Ayam dipelihara selama 2 bulan dengan pemberian pakan dan minum secara adlibitum. Pakan yang diberikan adalah pakan ayam broiler BR-1 dengan kandungan : air $12 \%$, PK 20,5 \%, LK 7,4 \%, SK $6 \%$, abu $8 \%$, Maduramicyn 5-6 ppm, zinc bacitracin 5-50 ppm. Bahan dan alat yang digunakan adalah kapur, sekam padi, dan bahan fumigasi kandang, sprayer, gelas ukur, timbangan (digital dan analitik), kandang litter dengan ukuran panjang 1,5 meter, lebar 0,5 meter, tinggi 1 meter, dan peralatan kandang. Penelitian ini dilaksanakan di Experimental Farm dan Laboratorium Produksi Ternak Unggas, Fakultas Peternakan, Universitas Jenderal Soedirman, Purwokerto, Jawa Tengah.

Penelitian dilakukan dengan metode eksperimental dengan peubah yang diukur dalam penelitian ini adalah produksi karkas yang meliputi bobot dan persentase karkas. Penelitian dilakukan dengan menggunakan Rancangan Acak Lengkap (RAL) dengan 5 macam perlakuan, yaitu jenis ayam sentul. Sa $=$ Ayam Sentul abu, $\mathrm{Sb}$ = ayam sentul batu, $\mathrm{Sd}$ $=$ Ayam sentul debu, $\mathrm{Se}=$ ayam sentul emas, $\mathrm{Sg}=$ ayam sentul geni. Model analisis yang diterapkan adalah analisis variansi dengan perlakuan apabila berpengaruh nyata, akan dilanjutkan dengan Uji Beda Nyata Jujur (BNJ).

\section{HASIL DAN PEMBAHASAN}

Perhitungan persentase karkas ayam sentul jantan umur 8 minggu berdasarkan data penelitian dapat dilihat sebagaimana pada Tabel 1. Hasil rata-rata bobot karkas keseluruhan yaitu sebesar 501,10 $\pm 64,00$ $\mathrm{g}$ dengan kisaran 466,80 g sampai 541,20 g. Bobot karkas (g) pada masing-masing perlakuan secara berurutan 542,2 (Sa), 514,40 (Se), 510,80 (Sg), 494,20 (Sd) dan 466,80 $\mathrm{Sb}$. Rataan bobot karkas berbagai jenis ayam sentul jantan selama penelitian lebih tinggi dari hasil penelitian Wahyu (2015) bahwa rataan bobot karkas ayam sentul pada umur 8 minggu adalah 439,55 $\mathrm{g}$.

Sedangkan untuk persentase karkas keseluruhan sebesar $65,53 \pm 4,87 \%$ dengan 
Tabel 1. Rataan bobot dan persentase karkas berbagai ayam sentul jantan periode awal

\begin{tabular}{clcc}
\hline \multirow{2}{*}{ No. } & \multirow{2}{*}{ Perlakuan } & \multicolumn{2}{c}{ Nilai } \\
\cline { 3 - 4 } & & Rataan Bobot $\pm \mathrm{SD}(\mathrm{g})$ & Persentase \pm SD $(\%)$ \\
\hline 1. & Ayam Sentul Abu (Sa) & $541,2 \pm 78,7$ & $66,47 \pm 0,879$ \\
2. & Ayam Sentul Batu (Sb) & $466,8 \pm 51,1$ & $63,53 \pm 2,145$ \\
3. & Ayam Sentul Sebu (Sd) & $494,2 \pm 79,0$ & $66,06 \pm 3,236$ \\
4. & Ayam Sentul Emas (Se) & $512,4 \pm 32,0$ & $64,43 \pm 6,357$ \\
5. & Ayam Sentul Geni (Sg) & $510,8 \pm 69,2$ & $67,53 \pm 8,584$ \\
\hline
\end{tabular}

Keterangan: $\mathrm{SD}=$ Simpangan baku

Tabel 2. Rataan bobot dan persentase dada berbagai ayam sentul jantan periode awal

\begin{tabular}{clcc}
\hline \multirow{2}{*}{ No. } & \multirow{2}{*}{ Perlakuan } & \multicolumn{2}{c}{ Nilai } \\
\cline { 3 - 4 } & & Rataan Bobot $\pm \mathrm{SD}(\mathrm{g})$ & Persentase $\pm \mathrm{SD}(\%)$ \\
\hline 1. & Ayam Sentul Abu (Sa) & $123,00 \pm 14,70$ & $22,87 \pm 1,92$ \\
2. & Ayam Sentul Batu (Sb) & $102,20 \pm 12,90$ & $21,88 \pm 1,39$ \\
3. & Ayam Sentul Sebu (Sd) & $113,80 \pm 17,90$ & $23,07 \pm 1,73$ \\
4. & Ayam Sentul Emas (Se) & $117,20 \pm 5,00$ & $22,90 \pm 0,95$ \\
5. & Ayam Sentul Geni (Sg) & $104,40 \pm 16,90$ & $20,51 \pm 2,63$ \\
\hline
\end{tabular}

Keterangan: $\mathrm{SD}=$ Simpangan baku

kisaran 63,53 \% sampai 67,53 \%. Pada penelitian ini persentase karkas adalah termasuk jantung, hati, dan gizzard. Hasil analisis variansi terhadap bobot karkas dan persentase karkas menunjukkan bahwa perlakuan berbagai ayam sentul berpengaruh tidak nyata $(\mathrm{P}>0,05)$ terhadap bobot dan persentase karkas ayam sentul jantan pada umur 8 minggu. Hasil ini lebih tinggi dari persentase karkas ayam sentul menurut penelitian Wahyu (2015) yang menunjukkan rataan sebesar $51,10 \%$.

Damayanti et al. (2013) menyatakan bahwa bobot potong dapat mempengaruhi persentase karkas. Laju pertumbuhan akan menunjukkan adanya pertambahan bobot badan yang pada akhirnya dihasilkan bobot potong. Bobot potong inilah yang nantinya akan mempegaruhi hasil persentase karkas. Bobot dan persentase karkas berbagai jenis ayam sentul umur 8 minggu cenderung tidak menunjukkan adanya perbedaan antara masing-masing jenis. Hal ini dipengaruhi oleh salah satu faktor genetik ayam sentul. Ayam sentul memiliki keragaman genetik cukup tinggi yang diperlihatkan dari variasi alel teramplifikasi cukup tinggi dan belum adanya alel sipesifikasi yang mencirikan suatu breed tertentu. Perbedaan breed pada ayam lokal baru tercermin dari penampilan fenotipenya saja sedangkan berdasarkan genetiknya masih perlu dilakukan seleksi. Perbedaan fenotipe ayam sentul diperlihatkan dari warna bulu berbagai ayam sentul. Menurut Soeparno (1994) penambahan bobot potong dipengaruhi oleh faktor genetik, lingkungan, nutrisi, umur, dan laju pertumbuhan yang akan meningkatkan persentase karkas.

Berdasarkan hasil penelitian (Tabel 2) menunjukkan bahwa rataan bobot dada berbagai jenis ayam sentul jantan umur 8 minggu adalah sebesar $112,10 \pm 15,20 \mathrm{~g}$ dengan kisaran 102,20 g sampai dengan 123,00 g. Rataan bobot dada (g) setiap perlakuan secara berurutan yaitu $123,00(\mathrm{Sa})$, 117,20 (Se), 113,80 (Sd), 104,40 (Sg), dan 102,20 (Sb. Rataan bobot dada hasil penelitian lebih rendah bila dibandingkan dengan hasil 
Tabel 3. Rataan bobot dan persentase pungung berbagai ayam sentul jantan periode awal

\begin{tabular}{clcc}
\hline \multirow{2}{*}{ No. } & \multirow{2}{*}{ Perlakuan } & \multicolumn{2}{c}{ Nilai } \\
\cline { 3 - 4 } & & Rataan Bobot $\pm \mathrm{SD}(\mathrm{g})$ & Persentase \pm SD $(\%)$ \\
\hline 1. & Ayam Sentul Abu (Sa) & $71,80 \pm 23,00$ & $13,09 \pm 3,52$ \\
2. & Ayam Sentul Batu (Sb) & $70,60 \pm 18,10$ & $15,39 \pm 4,79$ \\
3. & Ayam Sentul Sebu (Sd) & $64,40 \pm 17,50$ & $13,34 \pm 4,52$ \\
4. & Ayam Sentul Emas (Se) & $57,00 \pm 17,60$ & $11,03 \pm 2,93$ \\
5. & Ayam Sentul Geni (Sg) & $59,4 \pm 6,30$ & $11,80 \pm 2,09$ \\
\hline
\end{tabular}

Keterangan: $\mathrm{SD}=$ Simpangan baku

Tabel 4. Rataan bobot dan persentase sayap berbagai ayam sentul jantan periode awal

\begin{tabular}{clcc}
\hline \multirow{2}{*}{ No. } & \multirow{2}{*}{ Perlakuan } & \multicolumn{2}{c}{ Nilai } \\
\cline { 3 - 4 } & & Rataan Bobot \pm SD $(\mathrm{g})$ & Persentase \pm SD $(\%)$ \\
\hline 1. & Ayam Sentul Abu (Sa) & $67,40 \pm 12,4$ & $12,45 \pm 1,45$ \\
2. & Ayam Sentul Batu (Sb) & $61,60 \pm 5,80$ & $13,24 \pm 0,97$ \\
3. & Ayam Sentul Sebu (Sd) & $65,60 \pm 11,00$ & $13,35 \pm 1,95$ \\
4. & Ayam Sentul Emas (Se) & $66,20 \pm 7,20$ & $12,94 \pm 2,93$ \\
5. & Ayam Sentul Geni (Sg) & $61,00 \pm 4,90$ & $12,08 \pm 1,63$ \\
\hline
\end{tabular}

Keterangan: $\mathrm{SD}=$ Simpangan baku

penelitian Sari et al. (2016) yang menyatakan bahwa rataan bobot dada ayam kampung umur 7 minggu sebesar 212,00 g. Rataan persentase dada setiap perlakuan adalah sebesar 22,25 $\pm 1,93 \%$ dengan kisaran $20,12 \%$ sampai dengan $23,07 \%$. Berdasarkan hasil penelitian menunjukkan rataan persentase dada (\%) setiap perlakuan yaitu 23,07 ( $\mathrm{Sd}), 22,90(\mathrm{Se})$, 22,87 (Sa), 21,88 (Sb) dan 20,51 (Sg). Rataan tersebut lebih rendah bila dibandingkan dengan hasil penelitian Sari et al. (2016) yang menyatakan bahwa rataan persentase dada ayam kampung umur 7 minggu sebesar 52,7 $\%$.

Berdasarkan hasil penelitian (Tabel 3) menunjukkan bahwa rataan bobot punggung sebesar 64,60 $\pm 17,00 \mathrm{~g}$ dengan kisaran 57,00 g sampai 71,80 g. Persentase punggung (\%) setiap perlakuan yaitu 15,39 (Sb), 13,34 (Sd), 13,092 (Sa), 11,80 (Sg), dan 11,03 (Se). Rataan persentase punggung hasil penelitian ini lebih rendah bila dibandingkan dengan hasil penelitian Marsetyo et al. (2015) yang menunjukkan persentase punggung ayam kampung umur 8 minggu dengan pemberian ransum komersial adalah 23,6\%.

Hasil penelitian (Tabel 4) bobot ayam sentul umur 8 minggu diperoleh rataan bobot dan persentase sayap yaitu $64,40 \pm$ $8,40 \mathrm{~g}$ dengan kisaran $61,40 \mathrm{~g}$ sampai 67,40 g. Rataan bobot sayap hasil penelitian ini lebih rendah bila dibandingkan dengan hasil penelitian Kurniawan (2011), bobot ayam kampung umur 10 minggu yaitu 91,67 g. Rataan hasil persentase sayap ayam sentul umur 8 minggu adalah sebesar 12,81 \pm $1,45 \%$ dengan kisaran 12,08 sampai 13,35. Rataan persentase sayap hasil penelitian jauh lebih tinggi dari hasil penelitian Marsetyo et al. (2015) sebesar 15,5\%. Rataan bobot badan ayam sentul jantan umur 8 minggu sebagaimana pada Tabel 5 yaitu 199,50 $\pm 37,2$ g dengan kisaran 172, 80 g sampai 222,00 g. Rataan bobot paha hasil penelitian lebih rendah dibandingkan dengan hasil penelitian Kurniawan (2011) bobot karkas bagian paha keseluruhan ayam kampung umur 10 minggu yaitu 215,16 g. Rataan hasil persentase bobot 
Tabel 5. Rataan bobot dan persentase paha berbagai ayam sentul jantan periode awal

\begin{tabular}{clcc}
\hline \multirow{2}{*}{ No. } & \multirow{2}{*}{ Perlakuan } & \multicolumn{2}{c}{ Nilai } \\
\cline { 3 - 4 } & & Rataan Bobot $\pm \mathrm{SD}(\mathrm{g})$ & Persentase \pm SD $(\%)$ \\
\hline 1. & Ayam Sentul Abu (Sa) & $214,20 \pm 25,40$ & $39,99 \pm 5,30$ \\
2. & Ayam Sentul Batu (Sb) & $172,80 \pm 28,00$ & $37,23 \pm 6,25$ \\
3. & Ayam Sentul Sebu (Sd) & $199,80 \pm 51,72$ & $40,12 \pm 6,04$ \\
4. & Ayam Sentul Emas (Se) & $222,00 \pm 21,60$ & $43,37 \pm 5,05$ \\
5. & Ayam Sentul Geni (Sg) & $188,80 \pm 42,50$ & $37,29 \pm 8,36$ \\
\hline
\end{tabular}

Keterangan: $\mathrm{SD}=$ Simpangan baku

Tabel 6. Rataan bobot dan persentase jantung berbagai ayam sentul jantan periode awal

\begin{tabular}{clcc}
\hline \multirow{2}{*}{ No. } & \multirow{2}{*}{ Perlakuan } & \multicolumn{2}{c}{ Nilai } \\
\cline { 3 - 4 } & & Rataan Bobot $\pm \mathrm{SD}(\mathrm{g})$ & Persentase $\pm \mathrm{SD}(\%)$ \\
\hline 1. & Ayam Sentul Abu (Sa) & $4,48 \pm 1,17$ & $088 \pm 0,10$ \\
2. & Ayam Sentul Batu (Sb) & $3,96 \pm 0,68$ & $0,85 \pm 0,18$ \\
3. & Ayam Sentul Sebu (Sd) & $4,34 \pm 0,83$ & $0,88 \pm 0,14$ \\
4. & Ayam Sentul Emas (Se) & $3,82 \pm 0,72$ & $0,75 \pm 0,13$ \\
5. & Ayam Sentul Geni (Sg) & $4,50 \pm 0,57$ & $0,89 \pm 0,17$ \\
\hline
\end{tabular}

Keterangan: $\mathrm{SD}=$ Simpangan baku

paha ayam sentul umur 8 minggu diperoleh rataan persentase paha yaitu $39,62 \pm 6,24 \%$ dengan kisaran 37,23 sampai $43,47 \%$. Hasil penelitian lebih tinggi dari hasil penelitian Marsetyo et al. (2015) yang menyatakan persentase paha atas dan paha bawah ayam kampung umur 8 minggu adalah sebesar 35,4 $\%$.

Hasil analisis (Tabel 6, 7, dan 8) variansi bobot dan persentase jantung dan hati ayam sentul jantan umur 8 minggu menunjukkan bahwa berbagai jenis ayam sentul jantan tidak berpengaruh nyata $(\mathrm{P}>0,05)$ terhadap bobot dan persentase jantung dan hati. Rataan bobot jantung yaitu 4,29 $\pm 0,84 \mathrm{~g}$ dengan kisaran 3,82 sampai dengan 4,84 g. Rataan bobot jantung ayam sentul periode awal dari masing-masing perlakuan secara berurutan yaitu perlakuan 4,84 (Sa), 4,50 (Sg), 4,34 (Sd), 3,96 (Sb) dan 3,83 (Se). Berdasarkan hasil penelitan menunjukkan bobot jantung ayam sentul umur 8 minggu lebih besar dari hasil penelitian Sari et al. (2016) sebesar
2,00 g pada ayam kampung umur 7 minggu. Rataan persentase jantung yaitu $0,85 \pm 0,14$ $\%$ dengan kisaran $0,75 \%$ sampai dengan 0,89 $\%$. Dari hasil penelitian tersebut lebih besar dari hasil penelitian Sari et al. (2016) adalah 0,50 dari bobot potong ayam kampung umur 6 minggu.

Tabel 7 menunjukkan bobot hati dengan rataan 17,26 \pm 4,04 dengan kisaran 16,12 g sampai dengan 18,80 g, bobot hati (g) dengan masing-masing perlakuan secara berurutan 18,80 (Se), 18,28 (Sg), 16,56 (Sa), 16,56 (Sd) dan 16,12 (Sd). Rataan hati yaitu 3,42 \pm $0,70 \%$ dengan kisaran 3,06 \% sampai 3,65 $\%$. Persentase hati hasil penelitian ini lebih besar dibandingkan dengan rata-rata hati hasil penelitian Fathoni et al. (2016) yaitu 2,11 \%. Nickel et al. (1977) menyatakan bahwa bobot hati ayam berkisar antara 1,7 sampai 2,3\% dari bobot hidup.

Hasil penelitian bobot gizzard diperoleh rataan bobot yaitu 21,14 $\pm 5,74 \mathrm{~g}$ dengan kisaran 15,24 g samai 25,94 g. Bobot 
Tabel 7. Rataan bobot dan persentase hati berbagai ayam sentul jantan periode awal

\begin{tabular}{clcc}
\hline \multirow{2}{*}{ No. } & \multirow{2}{*}{ Perlakuan } & \multicolumn{2}{c}{ Nilai } \\
\cline { 3 - 4 } & & Rataan Bobot \pm SD $(\mathrm{g})$ & Persentase \pm SD $(\%)$ \\
\hline 1. & Ayam Sentul Abu (Sa) & $16,56 \pm 2,22$ & $3,06 \pm 0,14$ \\
2. & Ayam Sentul Batu (Sb) & $16,12 \pm 3,56$ & $3,46 \pm 0,70$ \\
3. & Ayam Sentul Sebu (Sd) & $6,56 \pm 1,78$ & $3,37 \pm 0,25$ \\
4. & Ayam Sentul Emas (Se) & $18,80 \pm 5,66$ & $3,65 \pm 0,98$ \\
5. & Ayam Sentul Geni (Sg) & $18,28 \pm 6,14$ & $3,58 \pm 1,08$ \\
\hline
\end{tabular}

Keterangan: $\mathrm{SD}=$ Simpangan baku

Tabel 8. Rataan bobot dan persentase gizzard berbagai ayam sentul jantan periode awal

\begin{tabular}{clcc}
\hline \multirow{2}{*}{ No. } & \multirow{2}{*}{ Perlakuan } & \multicolumn{2}{c}{ Nilai } \\
\cline { 3 - 4 } & & Rataan Bobot \pm SD $(\mathrm{g})$ & Persentase \pm SD (\%) \\
\hline 1. & Ayam Sentul Abu (Sa) & $25,94 \pm 5,36$ & $4,79 \pm 0,72$ \\
2. & Ayam Sentul Batu (Sb) & $15,44 \pm 1,80$ & $2,89 \pm 0,47$ \\
3. & Ayam Sentul Sebu (Sd) & $20,42 \pm 5,22$ & $4,09 \pm 0,46$ \\
4. & Ayam Sentul Emas (Se) & $20,88 \pm 5,30$ & $4,04 \pm 0,84$ \\
5. & Ayam Sentul Geni (Sg) & $23,00 \pm 6,00$ & $4,52 \pm 1,18$ \\
\hline
\end{tabular}

Keterangan: $\mathrm{SD}=$ Simpangan baku

gizzard menunjukkan bahwa berbagai jenis ayam sentul berpengaruh nyata $(\mathrm{P}<0,05)$ terhadap bobot dan persentase gizzard. Bobot dan persentase gizzard berbagai jenis ayam sentul jantan menunjukkan adanya perbedaan. Berdasarkan hasil penelitian Sa memiliki bobot badan tertinggi yaitu $813,60 \mathrm{~g}$ memiliki warna bulu yang lebih cerahdibandingkan dengan ayam sentul lainnya. Warna bulu berpengaruh terhadap kemampuan fisiologis ternak dalam penyerapan panas ke dalam tubuh. Ayam sentul yang memliki warna bulu lebih cerah akan lebih lambat dan lebih cepatdalam pelepasan panas ke dalam tubuh, sehingga berpengaruh terhadap konsumsi pakan. Konsumsi pakan akan mempenagruhi tingkat pertumbuhan dan pertambahan bobot badan. Semakin tinggi bobot badan makan akna semakin tinggi pula bobot dan persentase gizzard. Faktor lain yang mempengaruhi adalah pakan. Pakan yang digunakan selama penelitian (umur 0-8 minggu) dalam bentuk butiran (crumble) dengan kandungan serat kasar normal yaitu 5-6 \% yang akan mempermudah kerja dari gizzard dalam proses penghancuran pakan, sehingga bisa dikatakan bentuk pakan yang digunakan pada penelitian ini tidak memberikan pengaruh gizzard. Didukung pendapat Widianingsih (2008) yaitu bobot gizzard dapat dipengaruhi oleh kandungan serat kasar bahan pakan maka aktifitas gizzard juga semakin tinggi sehingga bobot gizzard juga semakin tinggi. Hasil penelitian Fathoni et al. (2016) menunjukkan bobot giblet (jantung, hati dan gizzard) ayam sentul umur 8 minggu secara berturut-turut adalah $5,41 \mathrm{~g}, 17,86 \mathrm{~g}$, dan $21,25 \mathrm{~g}$.

\section{KESIMPULAN}

Berdasarkan hasil penelitian, dapat dismpulkan perlakuan ayam sentul terhadap produksi karkas pada bobot dan persentase karkas, dada, punggung, sayap, paha, jantung, hati relatif sama, kecuali produksi karkas pada bobot dan persentase gizzard. Bobot dan 
persentase gizzard perlakuan Sa lebih tinggi dibandingkan perlakuan $\mathrm{Sb}$, sedangkan $\mathrm{Sd}$, $\mathrm{Se}$, dan $\mathrm{Sg}$ relatif sama.

\section{DAFTAR PUSTAKA}

Damayanti, V. 2003. Studi Perbandingan Persentase Karkas, Bagian-Bagian Karkas dan Non-Karkas pada Berbagai Unggas Lokal. Skripsi. Purwokerto, Jawa Tengah, Indonesia: Universitas Jenderal Soedirman.

Fathoni, R. M., W. Tanwiriah, dan H. Indrijani. 2016. Bobot Potong, Bobot Bagian Edible Dan In Edible Ayam Lokal Jimmy's Farm Cipanas Kabupaten Cianjur Jawa Barat. Students e-Journal, journal.unpad.ac.id. Fakultas Peternakan, Universitas Padjadjaran.

Hartono, E. F., Iriyanti, N. dan Suhermiyati, S. 2016. Efek Penggunaan Sinbiotik Terhadap Kondisi Miklofora dan Histologi Usus Ayam Sentul Jantan. Agripet, 97-105.

Kurniawan, H. 2011. Karkas dan Potongan Karkas Ayam Kampung Umur 10 Minggu yang Diberi Ransum Mengandung Bungkil Biji Jarak Pagar (Jatropa curcus L) Terfermentasi Rhizopus Oligosporus. Skripsi. Bogor, Jawa Barat, Indonesia: Institut Pertanian Bogor.

Marsetyo., Nuun, M. dan Hafsah. 2015. Pengaruh Level Penggunaan Daun Katuk (Saoropus androgynus) Pada Ransum Terhadap Penampilan Produksi dan Persentase Karkas Ayam Kampung. Online Jurnal Of Natural
Science Vol. 4(1) : 73-83, Maret 2015

Nataamijaya, A. G. 2010. Pengembangan Potensi Ayam Lokal untuk Menunjang Peningkatan Kesejahteraan Petani. Jurnal Litbang Pertanian, 131-138.

Nickel, R., A. Schummer., E. Seiferle, W. G. Siller, and P. A. L. Weight. 1977. Anatomy of The Domestic Bird. Verlag Paul Parey. Berlin.

Oluyemi, J.A. and Roberts, F. A. 1980. Poultry Production in Warm Wet Climates. London: The Mac Milan Press. Ltd.

Risnajati, D. 2012. Perbandingan Bobot Akhir, Bobot Karkas dan Persentase Karkas Berbagai Strain Broiler. Sains Peternakan, 11-14.

Sari., Harapin, H., dan Andi M. T. 2016. Kajian Produksi Karkas dan Non Karkas Ayam Kampung dengan Pemberian Ransum Komersial Tersubstitusi Tepung Kulit Biji Kedelai. Jitro Vol. 3 No. 3.

Soepamo. 1994. Ilmu dan Teknologi Daging. UCM Press. Yogyakarta.

Solikin, T., Tanwiriah, W. dan Sujana, E. 2016. Bobot Akhir, Bobot Karkas, dan Income Over Feed and Chick Cost Ayam Sentul Barokah Abadi Farm Ciamis. Students E-Journal, 1-9.

Wahyu, I. 2015. Bobot Potong, Karkas, Dan Income Over Feed Cost Ayam Sentul Jantan Pada Berbagai Umur Potong. Jurnal. Fakultas Peternakan Universitas Padjadjaran. Sumedang.

Widianingsih, N. M. 2008. Persentase Organ Dalam Broiler yang Diberi Ransum Crumble Berperekat Onggok, Bentonit, dan Tapioca. Skripsi. Institut Pertanian Bogor. 